\title{
Depression and determinant factors among elderly in India.
}

\author{
Dhasarathi Kumar* \\ Department of Public Health, SRM University, Chennai, Tamilnadu, India
}

Keywords: Depression, Geriatric population, Mental health.

Accepted on June 14, 2018

\section{Introduction}

Depression is a most common psychological disorder which is characterized by lack of interest in life, day to day activity, pleasure, guilty feeling, low self-esteem, sadness, poor memory, disturbed sleep pattern, poor appetite and tiredness. $20 \%$ of the geriatric population is facing mental or neurological problem, depression and dementia are the most common problem [1]. Depression is treatable but in $50 \%$ of the populations goes untreated and treatment is also not taken properly, it happen because of negligence, lack availability of services, social stigma and/or undiagnosed case [2] Depression is one of the main contributors to the mental health problems in India.

According to WHO 60 years and above 60 years of age group is considered as an elderly. During 2001 census in India overall constitution of elderly is 7\% and elderly population is increased by 2016 it is $8 \%$ [3], Overall proportion of the elderly population in world was $5.8 \%$ during 2000 and it is expected to increase to $8.7 \%$ by the year 2025 and $15.0 \%$ by the year of 2050 [4]. Geriatric populations are facing more physical and mental health problem than the younger population [5]. Almost all the system of the body are affected by ageing and aging involved with several physicals, metabolic and psychosomatic changes [6]. There are many studies which reveal that depression/ Psychological symptoms are more common among female than male; depression among females is 2.31 times higher than males [7].

Depression is not yet considered as an important health problem but it's a most common mental health problem among elderly; numerous studies were conducted to study the prevalence of depression but there are only a few studies done on determinant factors. The determinant factors of depression among elderly includes Gender (depression episodes are more common among female than males), Age group, Marital status (Married, Unmarried/Widowed), Type of family (Joint, Nuclear), Education (Illiteracy, Literacy), Occupation (Working, not working), Functional Impairments, Cognitive Impairments, those who are illiterate has the higher risk of depression [8], A study found that depression is more among widowed than the married, housing pattern also plays role in depression (people live in pucca houses they are less depressed than who lives in nonpucca houses), poverty, financially dependent geriatric populations are more depressed than the financially independent geriatric populations [9], Elderly living in nuclear family has more risk than the joint family, there is decreased consideration of elderly in nuclear family and urbanization also one of the major reason for increasing the number of nuclear family [10], feeling of ill, Absence of income \& staying without spouse [8], Feeling alone, financial insecurity-The level of depression is very high among the elderly those who are economically dependent, lack in geriatric friendly environment, Dependency in daily living-more than the Independent \& Partially dependent the totally independent population has depression [1,11], Genetic susceptibility, social isolation/social deprivation, limitation of daily living activity with frustrations, pain, Reduced satisfaction and quality of life, Chronic diseases, personality traits, Increased utilization of health and home care services are the determinant factors for depression [12-14].

Overall psychological status of elderly has been found to be average below average [9]. Nowadays Mental health has been gaining major attention and various treatments are available for depression, 10 percentage of population are taking antidepressant medications as well as psychotherapies and cognitive behavioural therapy (CBT). Psychotherapies and cognitive behavioural therapy (CBT) are equally effective as like antidepressant drugs [2]. Providing the health insurance scheme, geriatric clinics at PHC level, Creating the geriatric friendly environment, increasing the social recognition are the better intervention for depression and more than this providing love and care are the main approaches which will help to decrease the depression episode among elderly [1].

\section{Acknowledgments}

Many thanks to Dr. Alex Joseph, Prof. Bhagavandas and Dr. Arulmani $\mathrm{T}$ for insights and discussions.

\section{Conflict of Interest}

None declared

\section{References}

1. Lilian D'souza RT. Prevalence of depression among elderly in an urban slum of Bangalore, a cross sectional study. Inter J Interdisciplinary and Multidisciplinary Studies. 2015;pp:1-4.

2. WHO. Depression: Definition. Retrieved from World Health Organization. 2012.

3. India G.o. POPULATION COMPOSITION. 2011;pp:19-20.

4. Report W. Technical paper: Health care of the elderly in the Eastern Mediterranean Region: Challenges and Perspectives. WHO/EMR. 2003. 
5. Ibrahim NK, GT (n.d.). Morbidity profile of elderly attended/admitted in Jeddah health facilities, Saudi Arabia. WHO.

6. Kamala Krishnaswamy N. Dietary Guidelines for Indians. DietaryGuidelinesforNINwebsite.pdf: ICMR. 2011.

7. Abolfotouh DA. Psychosocial assessment of geriatric subjects in Abha City, Saudi Arabia. EMHJ. 2001;3:481-91.

8. Paramita Sengupta AI. Prevalence of Depression and Associated Risk Factors among the Elderly in Urban and Rural Field Practice Areas of a Tertiary Care Institution in Ludhiana. IJPH. 2017;pp:3-7.

9. Sanghamitra Maulik AD. Depression and its determinants in the rural elderly of West Bengal -a cross sectional study. IJBMR. 2012;pp:1300-02.
10. Suganathan S. A study on depression among elderly in a rural population of Tamil Nadu, India. Inter J Community Medicine and Public Health. 2016;pp:2571-4.

11. Na S. The Prevalence of Depression among the Rural Elderly in Chittoor District, Andhra Pradesh. J Clinical and Diagnostic Res. 2013;pp:1356-60.

12. Sekhon Harinder MS. A Study of Depression in Geriatric Population in a Rural Area of North India. Inter Publisher for Academic and Scient Resources. 2015;pp:26-18.

13. Sayer J. Mental health: new understanding, new hope. Geneva, World Health Organization, 2001: The world health report 2001.

14. Anantlaxmi Ananthram Goud NS. Prevalence of depression in older adults living in old age home. Inter Archives of Integrated Med. 2015;pp:1-5.

\section{*Correspondence to:}

Dhasarathi Kumar

Department of Public Health

SRM University

Chennai, Tamilnadu

India

E-mail: dhasarathykumar@gmail.com 